\title{
Comparative Analysis of the Production Process of a Flange-Type Product by the Hybrid and Traditional Method with the Use of Simulation Methods
}

\author{
Agnieszka Terelak-Tymczyna ${ }^{1 *}$, Emilia Bachtiak-Radka ${ }^{1}$, Andrzej Jardzioch ${ }^{1}$ \\ 1 Faculty of Mechanical Engineering and Mechatronics, Department of Production Management, \\ West Pomeranian University of Technology in Szczecin, al. Piastów 19, 70-310 Szczecin, Poland \\ * Corresponding author's e-mail: aterelak@zut.edu.pl
}

\begin{abstract}
In the era of Industry 4.0, the digitization of production processes is one of the important elements contributing to the reduction of uncertainty related to the implementation of new production methods. The worldwide epidemic situation and its constraints have resulted in supply chain continuity problems. These problems make enterprises look for the possibility of producing products that they need at the moment and which they cannot obtain from the market. In special cases, this may also apply to spare parts necessary to maintain the continuity of production. The main reason for research on comparing production processes is meeting the challenges related to the pandemic situation and problems in maintaining timeliness, flexibility, and continuity of the supply chain. The first stage of the research was to visualize the course of the process and determine the lead times for both production methods. For further analysis, a digital process model was used to compare the hybrid and the classical method to check the viability of the interchangeability of methods for the production process of the flange part. The interchangeability of production methods was dictated by problems related to the supply of components for the execution of orders. The article simulates the model for unit and small-lot production in batches of 10 and 100 pieces, considering such aspects as: order completion time, energy consumption of the process, production costs, taking into account the classic and hybrid methods. The conducted research was aimed at determining the profitability of the production of flange-type products by means of classical processing and hybrid and checking the interchangeability of production methods in accordance with quality requirements as well as reducing uncertainty with the implementation of new production systems in changing market conditions. The simulations show that the use of hybrid production is recommended for unit production. In the case of small-lot production, already with 10 items, production in the traditional process is $21 \%$ cheaper, and for the production of 100 items, the cost of traditional production is reduced by $33 \%$ compared to hybrid production.
\end{abstract}

Keywords: machining, hybrid machining, VSM, SLM, process simulation, cost of the production, energy analysis.

\section{INTRODUCTION}

The development of the Industry 4.0 concept forces enterprises to adapt to changing market conditions. An additional challenge for the socio-economic environment is the epidemic situation in Europe and in the world, which is related to "operating restrictions" in a wide range of industries [1-5]. In the series of articles Sarkis $[1,2]$, method management were presented of modern production processes and supply chain in the COVID-19 crisis. Describes problems at the macroeconomic level, will the world return to global supply chain systems and lean JIT practices after the pandemic. Additionally, it examines how companies will manage their inventory, whether the resilience of the supply chain will require flexibility, and whether there will be more energy losses and waste from excess inventory. In the work of Kimura et al. [3] emphasized that the stability of the global value chains (GVC) network is of key importance during a pandemic 
in terms of securing the risk of disruptions in the procurement of key medical and health products, as well as maintaining service links with manufacturing, such as the logistics sector. In the work of Karmaker et al. [4], examines the challenges posed by the COVID-19 pandemic for a sustainable supply chain (SCS) to deal with supply chain disruptions in a pandemic. This study reveals the influential relationships and necessary connections between drivers using fuzzy total interpretive structural modeling (TISM) to improve the SCS in the context of COVID-19. In the work of Chowdhury et al. [5], a literature review was carried out on previous outbreaks and other disruptions to supply chain disciplines. Taking the results of these articles together with the COVID-19 pandemic analysis into account, this gave authors guidance for further research. The above articles highlighted the problem related to the flexibility of production processes in the times of the COVID-19 crisis.

Despite this, entrepreneurs have to create new business models and implement innovations quickly reorganize production processes and flexibly adjust the functioning of enterprises and offered services to the conditions of the changing competitive and market environment [6-9]. In the article by Chromjakov et al. [6] describes the benefits of using the Industry 4.0 concept, which enables the improvement of productivity and efficiency, comprehensively, production value chains, allow you to focus on creative and strategic business activities. In the work of Geissdoerfer et al. [7] discusses the sustainability performance of the circular business models (CBM) and circular supply chains necessary to implement the concept on an organizational level and proposes a framework to integrate circular business models and circular supply chain management towards sustainable development. The conclusion was that circular business and the circular supply chain help in realizing sustainability ambitions. Authors Breier et al. [8] prove in the article that business model innovation is a potential solution to overcome the crisis in the hotel industry, as well as in the situation of fighting the consequences of the COVID-19 crisis. Haaker [9] the research provides insights into the commonalities and discrepancies of IoT-based business models. Also, it provides a novel application of morphological analysis to business model innovation to create a generic business model for IoT applications in emerging markets. According to the concept of Industry 4.0, among others Martinez-Hernandez et al. [10] presents a conceptual model for characterizing localized production systems, and Hulkó et al. [11] describes virtual software environments for technological process control. The literature describes also problems related to the design of the synthesis of future mechatronic robotic objects, the so-called e-facilities for product life cycle analysis [12]. In the literature, you can find examples of modeling e-business processes and the extension of models to supply chains, as well as descriptions of the benefits of applying a new methodological approach to the development of static and dynamic reusable simulation models [13] and likewise in [14], which are a key technology in the context of Industry 4.0.

The literature contains many approaches to simulating, quickly assessing system performance, and making decisions based on optimization criteria. Moreover, the simulation has been identified as one of the pillars of the Industry 4.0 revolution. However, the lack of a generally recognized approach and methodology for dealing with real-time decision making through simulation is evident. In the coming years, simulation approaches can and should play a key role in industry 4.0 in the epidemic situation in Europe and the world [15-19]. This work [15] develops a novel validation procedure inspired by signal-processing theory and a novel approach called quasi Trace Driven Simulation. The procedure is coherent with a Real-Time Simulation framework since it does not require large datasets to provide a good solution. The approach has been tried on test cases which demonstrated its applicability to a manufacturing environment. This paper [16] analyses the current research context with a brief state of the art on existing approaches, includes considerations about the issues for implementing Real-Time Simulation (RTS) concepts and their current state of development. Finally, it outlines research directions for the simulation community. Malega et al. [17] the main goal is to show that in a concrete company case, the simulation-based approach provides increased productivity. The presented study proposes the practical application of the Tecnomatix software used in the research to optimize the production system. Ultimately, it was showed that the simulation approach to the production line control provides rather effective solutions when compared to the intuitive one based 
on trial-and-error experience. The improvement includes a significant shortening of the production cycle and increase in productivity. To identify bottlenecks in the manufacturing process in article Gola et al. [18], we ran computer simulations in which the course of the manufacturing process was modelled and simulated for 2-, 3-, 4- and 5-stage RMS structures using Tecnomatix Plant Simulation software. The article Kikolski [19] presents possibilities of applying computer simulation models in studying chosen production scenarios. The basic methods of research used in the study were literature studies and computer simulation. The research Kłos et al. [20] the main goal was to analyse the impact of buffer allocation on the behaviour of a general, parallel manufacturing system. The methodology for preparing simulation experiments is here proposed. In the paper Grabowik et al. [21] a comparison analysis of simulations results got for the model of a real production line is performed. The main motivation of the paper was to compare simulation results obtained in the two simulation tools it is FlexSim and Tecnomatix Plant Simulation in order to state if the simulation quality depends on the choice the simulation tool. It the paper Zhang [22] was review and summarizes the research and application of modeling and simulation technology in manufacturing, and analyzes typical simulation techniques in manufacturing from aspects of manufacturing unit simulation, manufacturing integrated simulation and manufacturing intelligent simulation. The paper Strnad [23] was described how innovation, spurred by crisis brought about by the current pandemic situation, can be implemented to the supply chain in the automotive sector.

Also, ecological aspects, including energy consumption of production processes, are an important element of Industry 4.0 and the era of digitization of enterprises. In the literature on the subject, you can find many scientific studies devoted to the possibilities of optimizing the machining process in terms of energy efficiency, among others by collecting and processing large amounts of data on power and operations [24] and the use of modern methods [25], including artificial intelligence methods for planning. Such research was carried out by, among others Al Hazza et al., Who in the publication [26] presented the optimal parameters of continuous treatment in relation to the minimum cost of energy consumption while maintaining the surface roughness within the acceptance range using a multitasking genetic algorithm. Genetic algorithms were also used by Datta et al. in [27], where he presented the optimization of machining parameters based on the Multiobjective Evolutionary Algorithm. Research on the introduction of energy consumption for the planning of the treatment process was also carried out by Newmann et al. [28]. Whereas Zhang at al. In [29], he worked on a multitasking model of process optimization considering high efficiency, low energy consumption and low carbon dioxide emissions. The paper shows that high feed rates and a large cutting width can bring benefits for all the parameters considered, i.e., performance, energy consumption and carbon dioxide emissions, if the limitations can be met. In the literature, we can also find online optimization methods using real-time control. Research on component-based energy modeling methodology to implement the online optimization needed for real-time control can be found in Shin at al. [30].

The comparative analysis of classical and hybrid processing was carried out by Grzesiak et.al. [31], who in the article presented a comparison of the production of one product with the classic method and the hybrid method. In the literature on the subject, no issues related to the modeling and simulation of both processes for different production batches have been found, which allows to determine the profitability of production and reduce uncertainty with the implementation of new production systems in changing market conditions. For this reason, the article analyzes the production process of a flange-type product using simulation modeling in order to build a digital model in accordance with the concept of Industry 4.0, thanks to which it will be possible to react quickly to changes in the production process and flexibly adapt the possibilities of using traditional machining and hybrid machining methods. combining additive manufacturing with machining.

The main reason for research on comparing production processes is meeting the challenges related to the pandemic situation and problems in maintaining timeliness, flexibility, and continuity of the supply chain. The first stage of the research was to visualize the course of the process and determine the lead times for both production methods. For further analysis, a digital process model was used to compare the hybrid and the classical method to check the viability of the 
interchangeability of methods for the production process of the flange part. The interchangeability of production methods was dictated by problems related to the supply of components for the execution of orders. The article simulates the model for unit and small-lot production in batches of 10 and 100 pieces, considering such aspects as: order completion time, energy consumption of the process, production costs, taking into account the classic and hybrid methods. The selected parameters were aimed at indicating the profitability of the production of a shield type product, while maintaining the required quality parameters for two production methods. The conducted research was aimed at determining the profitability of the production of flangetype products by means of classical processing and hybrid and checking the interchangeability of production methods in accordance with quality requirements as well as reducing uncertainty with the implementation of new production systems in changing market conditions.

\section{MATERIAL AND METHOD}

To analyze the subject of the article, a representative part (Fig. 1) was selected, which was a disc element made of general purpose 17-4PH stainless steel. The geometrical shape of the element along with the required deviations in dimensions and shapes as well as the roughness are shown in Figure 1. The technical drawing was analyzed in order to meet the quality of the requirements and to determine the comparative elements. The geometric shape of the element along with the required deviations of dimensions and shapes are shown in Figure 1. To be able to compare the interchangeability of the type of production process of a flange-type product without cost, a digital model was proposed in accordance with the concept of Industry 4.0. For the purpose of developing the digital model, two copies of the parts were made using two different production processes, called the "classical process" and the "hybrid process" (Table 1).

During the implementation of both processes, data on processing time, energy consumption, labor consumption were collected, and the quality of the obtained surfaces was measured.

The manufacturing process scheme, as well as the NC programs, were prepared by a skilled technologist. The classic production process was entirely realized using a CTX Ecoline turning center with Y-axis positioning and driven tools. In the case of the classic process, the semi-finished product selected by the tech-nologist was a rod with a diameter of $110 \mathrm{~mm}$. The hybrid process was carried out using the SLM Realizer II device and the CTX Ecoline turning center. In the case of a hybrid process, the raw material was metal powder. For roughing, CCMT 120404EN-SM CTC2135 plates were selected, for finishing the DCMT 11T304ENSM CTC2135 plate. The axial borehole was

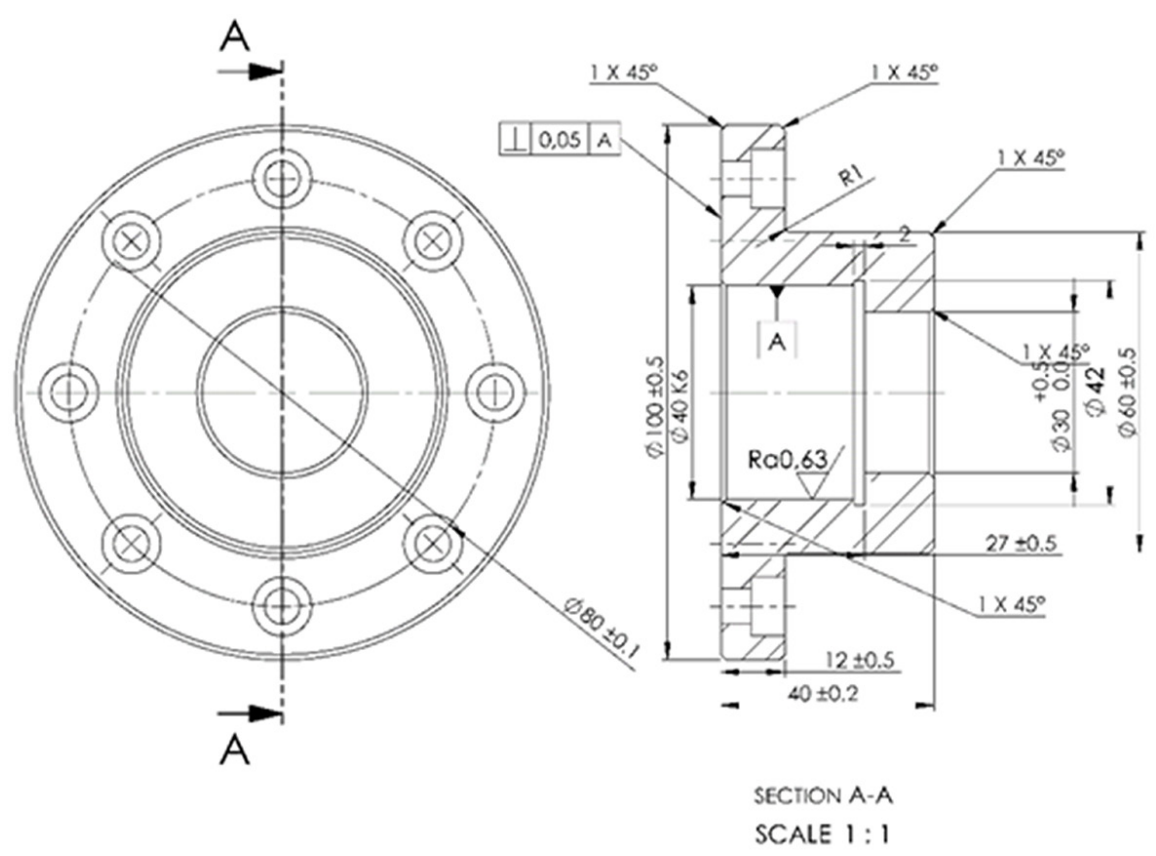

Fig. 1. Geometric shape of the element 
Table 1. Manufactured items

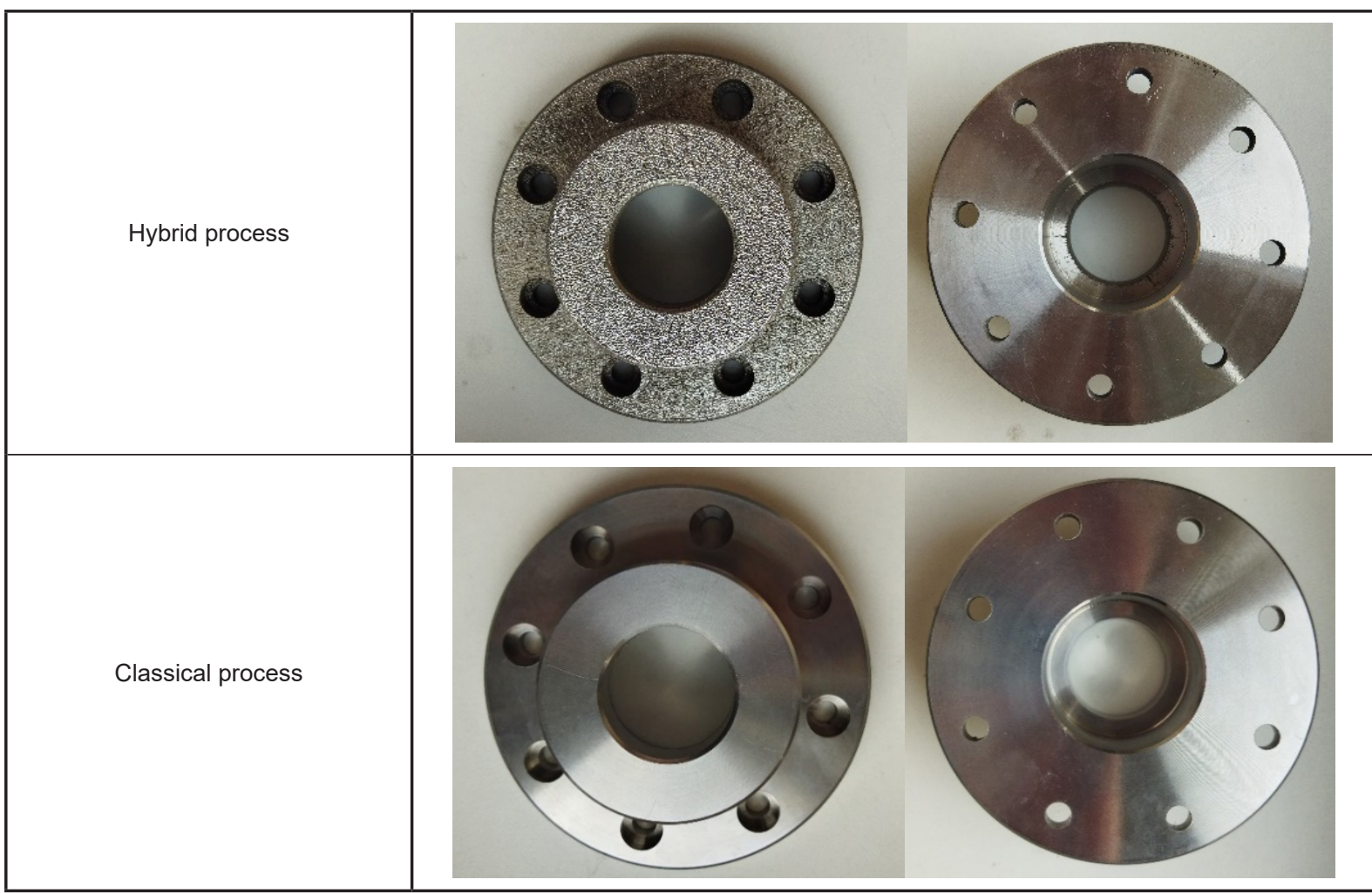

drilled with a folding drill bit XOMT 060304SN CTPP430. Drill holes were drilled with carbide drill bits WPC-VA.6,60.R.3D.IK.DIN6535.HA TIALN, and deepening in holes with countersink SE.N. 6.40X11.00.180 ${ }^{\circ}$.DF.DIN373.

Electricity consumption in both processes was measured with the Lumel ND 20 recorder. The current was measured with the use of transformers, while the voltage was measured directly. The results were recorded using the PowerVIS recorder software.

\section{RESULTS}

In order to better visualize the course of the process and determine the implementation times and value addition, the value stream was mapped for both realized production processes, which was then modified for the production in batches of 10 and 100 pieces. VSM for piece production was done in real time. The use of a value stream map was necessary to identify the existing processes along with the use of the timing method
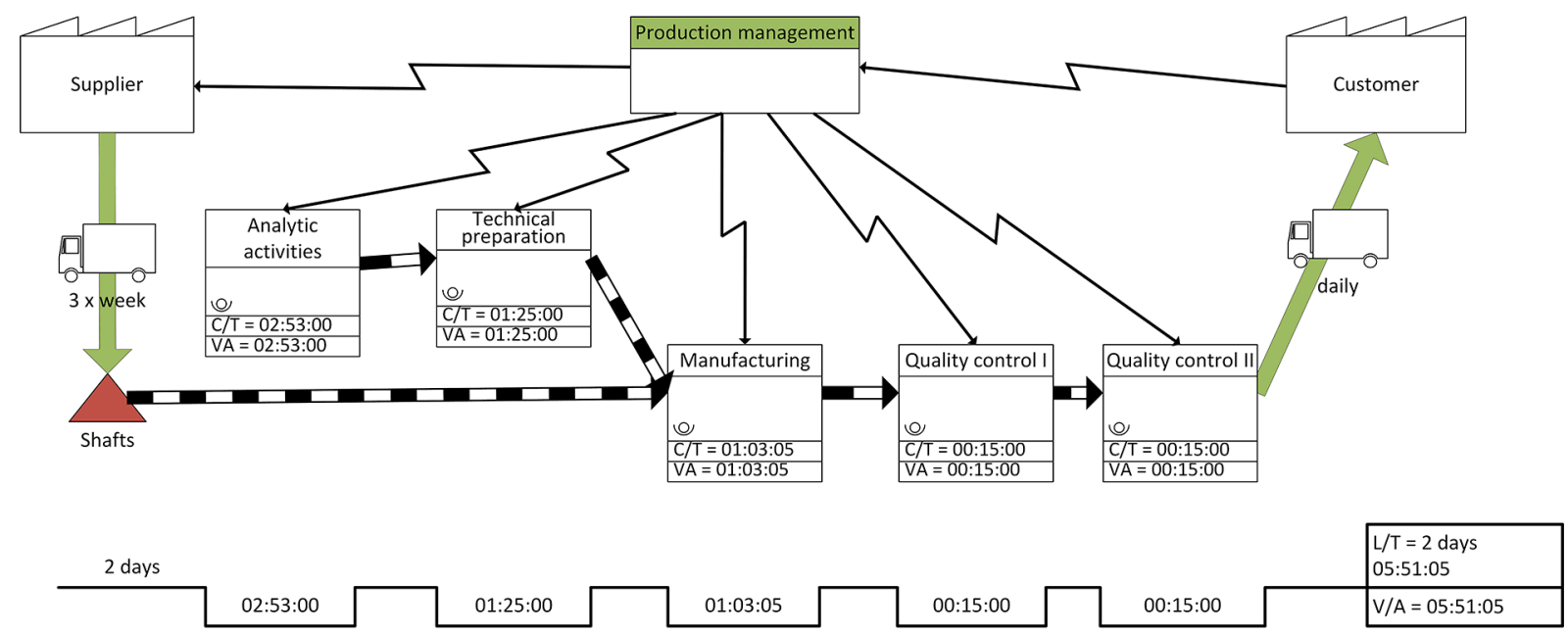

Fig. 2. Value Stream Mapping for classic manufacturing process for a unit production 


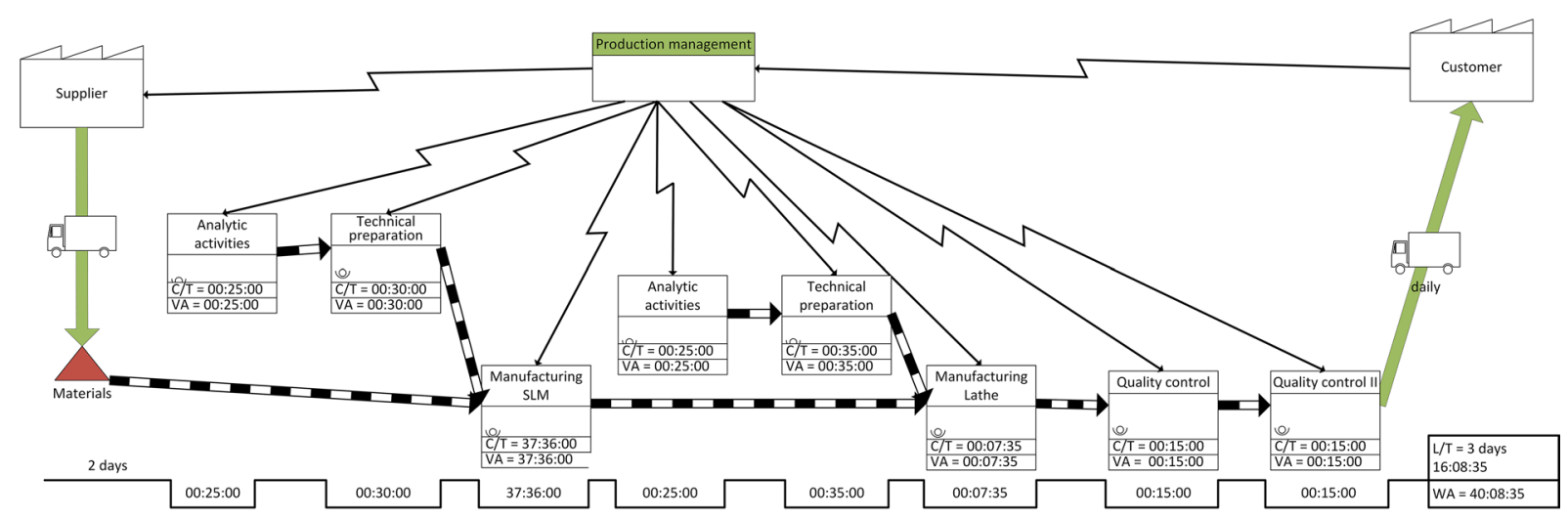

Fig. 3. Value Stream Mapping for hybrid manufacturing process for a unit production

(measuring the time of individual activities). The results of value stream mapping for unit production are shown in Figures 2-3. According to the data presented on VSM maps, the added value in the classical process for the production of one item is $31.9 \%$ of the total execution time, while for the hybrid process it is $45.5 \%$. Which proves the greater efficiency of the hybrid process for unit production. Despite the longer lead time for hybrid production, the time spent on adding value to the product in relation to the total amount of work time is $13.6 \%$ greater than for classic production. This situation changes for the production in batches of 10 and 100 pieces due to the formation of inter-operational stocks and the occurrence of a bottleneck in the form of the SLM process, the classic process is characterized by a higher process efficiency index. For the production in series of 10 and 100 pieces, the labor time for the classic process is greater than for the hybrid process in relation to the total implementation time and amounts to $1.5 \%$ for traditional processing and $1.07 \%$ for hybrid processing, respectively.

\section{Initial assumptions for the research}

In order to meet all the guidelines for the conducted experiment, in the article, according to Grzesiak et al. [31] the main assumptions were made, which are presented in Table 2. production costs, taking into account the labor costs of the operator, technology and quality controller, as well as the costs of energy, materials and tools used.

The initial assumptions for the analyzes carried out were to omit the costs of purchasing and maintaining machine tools and devices,

Table 2. The unit cost of production (workpiece)

\begin{tabular}{|c|c|c|c|}
\hline Description of the cost & Classic manufacturing process & Hybrid manufacturing process & Unit \\
\hline Operator's work * & 27.50 & 28.13 & PLN/h \\
\hline Technologist's work ** & 37.50 & 37.50 & PLN/h \\
\hline Quality controller's work *** & 26.88 & 26.88 & $\mathrm{PLN} / \mathrm{h}$ \\
\hline Materials **** & 228.58 & 363.57 & PLN \\
\hline Cutting tools ***** & 547.68 & 128.44 & PLN \\
\hline Electricity $* * * * * *$ & 0.6203 & 0.6203 & PLN/kWh \\
\hline \multicolumn{4}{|c|}{$\begin{array}{l}{ }^{*} \text { Average salary of CNC Machine Tool Operator (classic manufacturing process) and CNC Machine Tool Operator (hybrid } \\
\text { manufacturing process): source: https://zarobki.pracuj.pl/ }\end{array}$} \\
\hline \multicolumn{4}{|c|}{ ** Average salary of Process Technologist: source: https://zarobki.pracuj.pl/ } \\
\hline \multicolumn{4}{|c|}{ *** Average salary of Quality Controller: source: https://zarobki.pracuj.pl/ } \\
\hline \multicolumn{4}{|c|}{$\begin{array}{l}* * * * \text { The cost of the rolled rods of circular with a diameter of } 110 \mathrm{~mm} \text { (classic manufacturing process) and } 1.07 \mathrm{~kg} \text { of metal } \\
\text { powder (hybrid manufacturing process) }\end{array}$} \\
\hline \multicolumn{4}{|c|}{$\begin{array}{l}* * * * * \text { The cost of cutting tools: For roughing, CCMT 120404EN-SM CTC2135 plates were selected, for finishing the DCMT } \\
\text { 11T304EN-SM CTC2135 plate. The axial borehole was drilled with a folding drill bit XOMT 060304SN CTPP430. Drill holes } \\
\text { were drilled with carbide drill bits WPC-VA.6,60.R.3D.IK.DIN6535.HA TIALN and deepening in holes with countersink SE.N. } \\
6.40 X 11.00 .180^{\circ} \text {.DF.DIN373. }\end{array}$} \\
\hline \multicolumn{4}{|c|}{$\begin{array}{l}* * * * * \text { The cost of consumption electricity. For the calculations, the cost for the tariff was assumed C11 (1 kWh =0.6203 PLN) } \\
\text { source: https://www.enea.pl/dlafirm/obsluga_klienta_i_kontakt/2021/taryfa_abcr_2021_0906.pdf }\end{array}$} \\
\hline
\end{tabular}


and to omit the costs of purchasing technological equipment that did not wear out during the experiment. The analysis includes all operations related to the preparation and implementation of both production processes, as shown in Figures $4 \div 5$. The data presented in Figures 4 and 5 do not include the time needed for quality control of the required quality parameters as well as packaging and shipping, which were included in the stream map values (Figures 2-3).

Tecnomatix Plant Simulation 16 software was used to develop the digital twin model for both "classical" and "hybrid" processes.

\section{Digital model}

To determine the profitability of the production of flange-type products by classical and hybrid processing, to check the interchangeability of production methods in accordance with quality requirements and to reduce uncertainty in the implementation of new production systems in changing market conditions, models of real processes were designed in the Plant Simulation program. The process models designed in Plant Simulation are consistent with their course and the input parameter of the lead time presented in Figures 2 and 3. First, technological parameters are determined as part of the technical preparation of production, and then machining operations are carried out. After processing, there is a quality control. $100 \%$ of the workpieces are checked. Figures 6 and 7 shows two digital models of the implemented processes made in the Plant
Simulation program. The model shown in Figure 6 shows classical machining, in which the technological process takes place only on a CNC lathe. The model shown in Figure 7 shows the flow of workpieces in the case of the proposed hybrid machining. In this case, the technological process is carried out in two stages. The basic technological operation is performed on the SLM printer (4) and then the machining operation is performed on a CNC lathe (5).

Within the scope of the performed analyzes on a digital model, it will be possible to verify a quick response to changes in the production process and to flexibly adjust the possibilities of using traditional machining and a hybrid machining method combining additive manufacturing with machining.

\section{Obtained results}

The analysis was carried out with regard to the criterion of the size of the production batch, considering such aspects as: order execution time, energy consumption of the process, quality parameters of the obtained surfaces and the costs of producing elements. From the simulation tests performed (Table 3), the order completion times were obtained similar to those presented in VSM. The difference is in the range of $1-1.5 \%$, which results from the calculation of the storage time for individual production orders (10 and 100 pieces). The presentation of data in Table 3 was showed that the added value for the hybrid process with the increase of the production batch compared to the classical process decreases

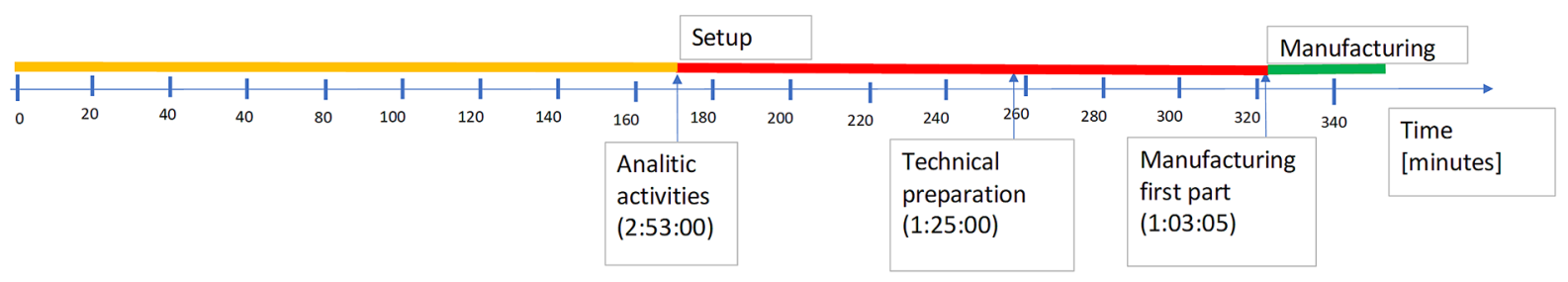

Fig. 4. Time necessary to prepare and run for the "classical process"

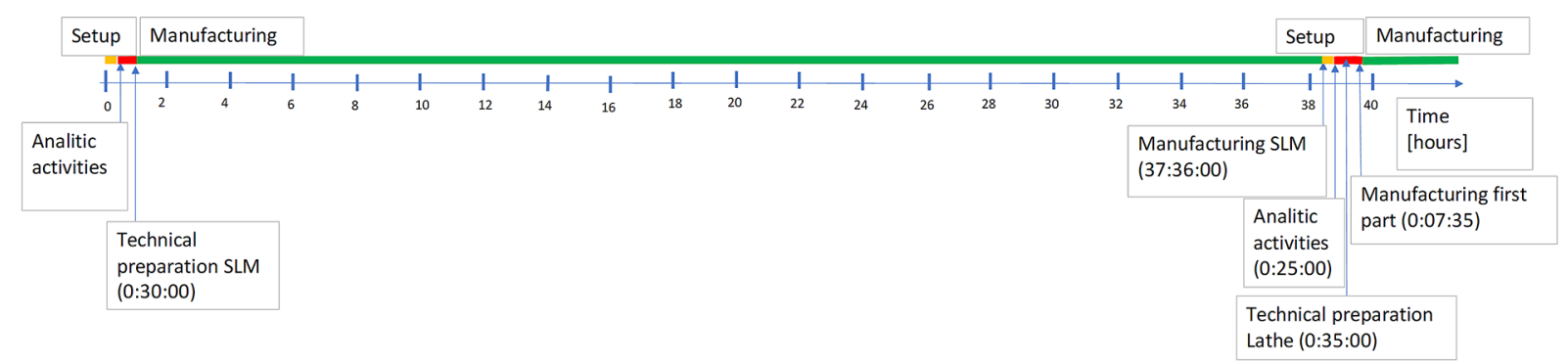

Fig. 5. Time necessary to prepare and run for the "hybrid process" 


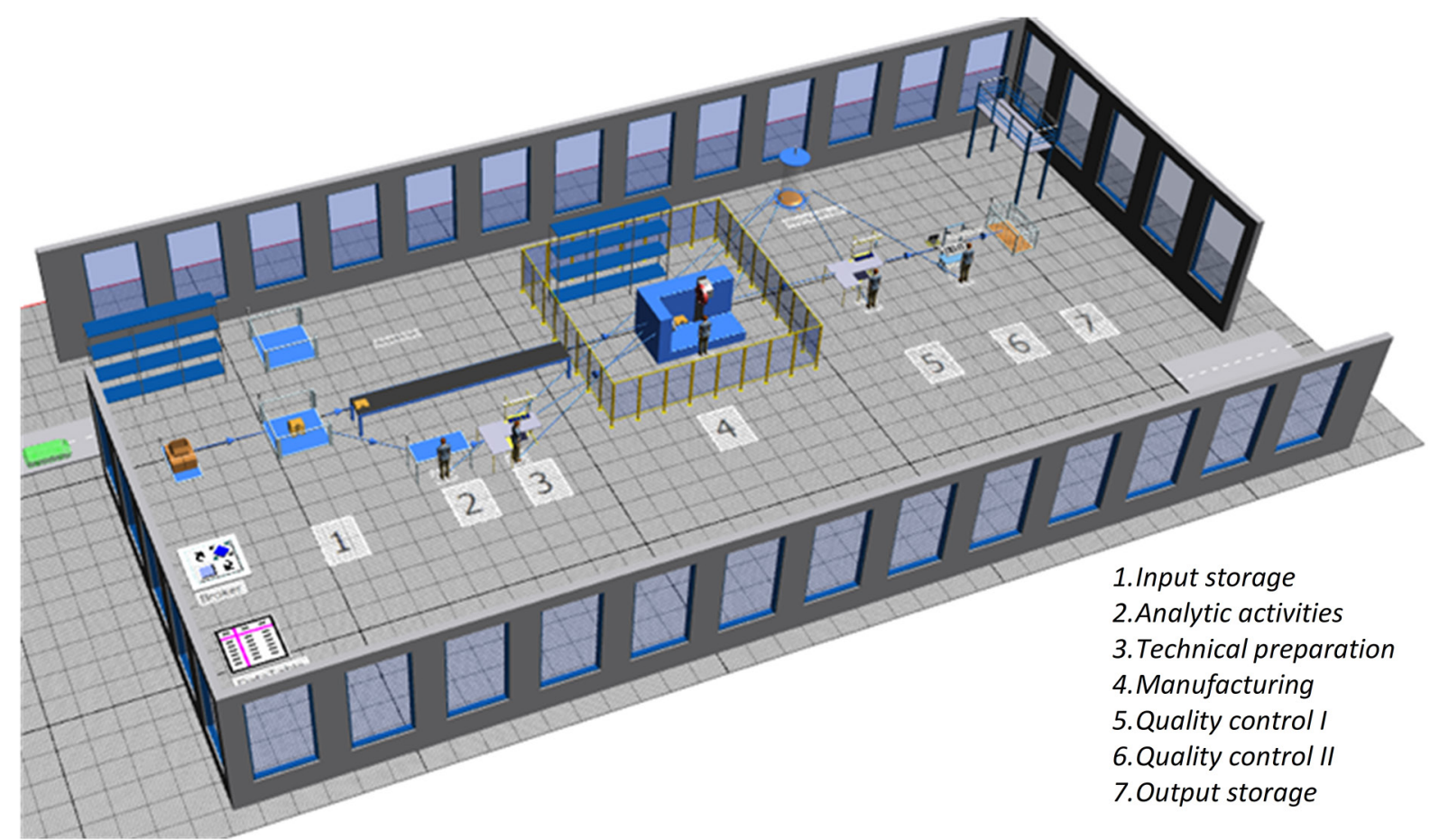

Fig. 6. Simulation model showing "classical manufacturing process"

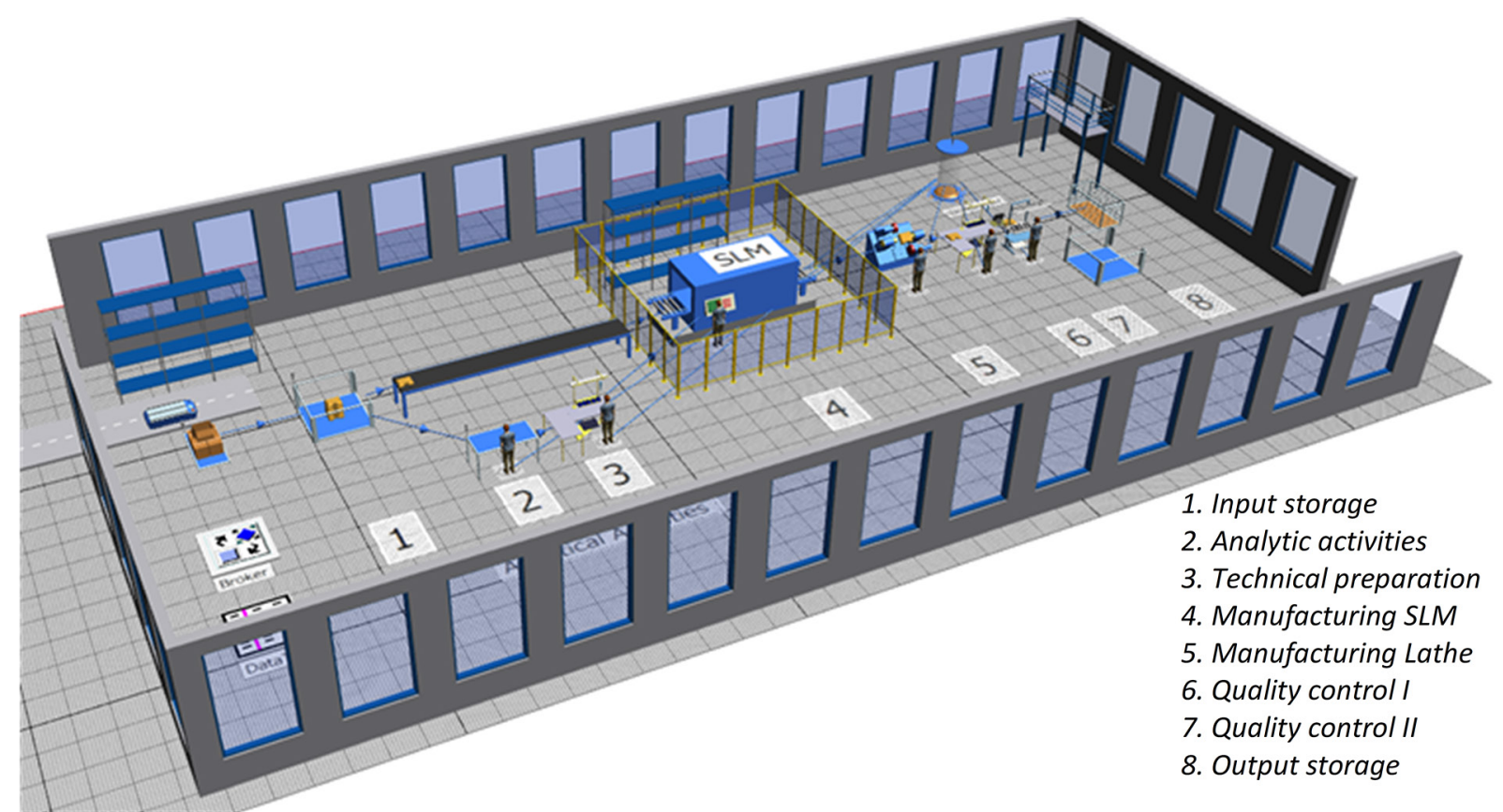

Fig. 7. Simulation model showing "hybrid manufacturing process"

much faster. This means higher costs associated with a waste of waiting due to the bottleneck for hybrid manufacturing process.

The percentage of working time and waiting time were analyzed for individual production stations and for classic and hybrid manufacturing process (Figure 8), the largest share of labor time was characterized accordingly for unit production: for the classic production of analytical activities, and for the hybrid production - production with the SLM. The largest share of labor time was characterized accordingly for small-lot production in batches of 10 and 100 pieces: for classic manufacturing process on the machine tool for hybrid production - production with the additive manufacturing SLM. This is due to large share of manufacturing and from the fact that regardless 
Table 3. List of parameters of the production process

\begin{tabular}{|c|c|c|c|c|c|c|c|}
\hline $\begin{array}{l}\text { Production } \\
\text { type }\end{array}$ & $\begin{array}{l}\text { Production } \\
\text { value }\end{array}$ & $\begin{array}{c}\text { Production time } \\
\text { [day: hours: minutes: sec] }\end{array}$ & Throughput & $\begin{array}{l}\text { Throughput } \\
\text { per hour }\end{array}$ & Production & Storage & $\begin{array}{l}\text { Value } \\
\text { added }\end{array}$ \\
\hline \multirow{5}{*}{$\begin{array}{c}\text { Classic } \\
\text { manufacturing }\end{array}$} & $1 \mathrm{psc}$ & 05:51:05 & 1 & 0.17 & $100.00 \%$ & $0.00 \%$ & $100.00 \%$ \\
\hline & \multirow{2}{*}{$10 \mathrm{pcs}$} & \multirow{2}{*}{$15: 18: 50$} & 1 & 0.07 & $100.00 \%$ & $0.00 \%$ & $100.00 \%$ \\
\hline & & & 9 & 0.59 & $13.97 \%$ & $86.03 \%$ & $13.97 \%$ \\
\hline & \multirow{2}{*}{100 pcs } & \multirow{2}{*}{ 4:13:56:20 } & 1 & 0.01 & $100.00 \%$ & $0.00 \%$ & $100.00 \%$ \\
\hline & & & 99 & 0.90 & $19.52 \%$ & $80.48 \%$ & $11.92 \%$ \\
\hline $\begin{array}{l}\text { Production } \\
\text { type }\end{array}$ & $\begin{array}{l}\text { Production } \\
\text { value }\end{array}$ & $\begin{array}{c}\text { Production time } \\
\text { [day: hours: minutes :sec] }\end{array}$ & Throughput & $\begin{array}{l}\text { Throughput } \\
\text { per Hour }\end{array}$ & Production & Storage & $\begin{array}{l}\text { Value } \\
\text { added }\end{array}$ \\
\hline \multirow{5}{*}{$\begin{array}{c}\text { Hybrid } \\
\text { manufacturing }\end{array}$} & $1 \mathrm{psc}$ & 1:16:08:35 & 1 & 0.02 & $100.00 \%$ & $0.00 \%$ & $100.00 \%$ \\
\hline & \multirow{2}{*}{$10 \mathrm{pcs}$} & \multirow{2}{*}{$15: 16: 37: 35$} & 1 & 0 & $100.00 \%$ & $0.00 \%$ & $35.08 \%$ \\
\hline & & & 9 & 0.02 & $17.55 \%$ & $82.45 \%$ & $17.55 \%$ \\
\hline & \multirow{2}{*}{100 pcs } & \multirow{2}{*}{$156: 16: 37: 35$} & 1 & 0 & $100.00 \%$ & $0.00 \%$ & $35.08 \%$ \\
\hline & & & 99 & 0.03 & $1.99 \%$ & $98.01 \%$ & $1.99 \%$ \\
\hline
\end{tabular}

Classic manufacturing - 1 pcs

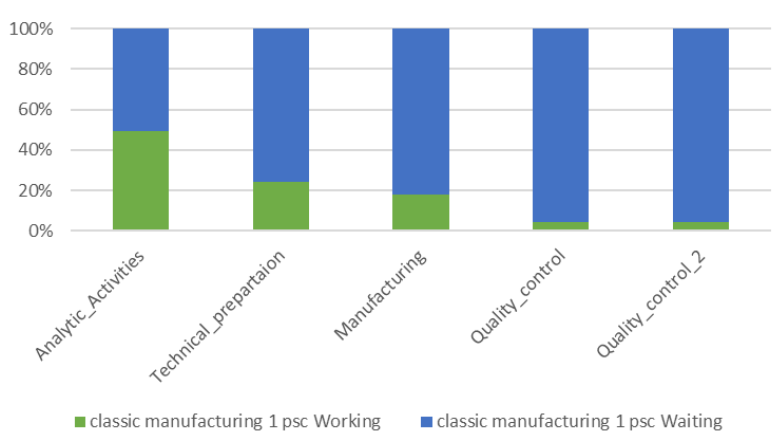

Classic manufacturing - 10 pcs

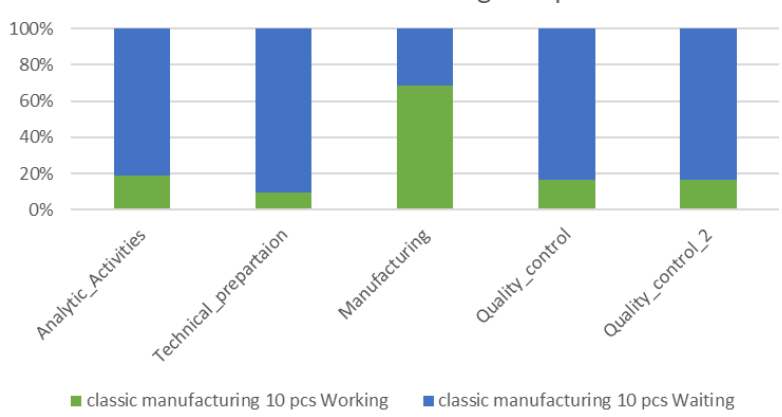

Classic manufacturing - 100 pcs

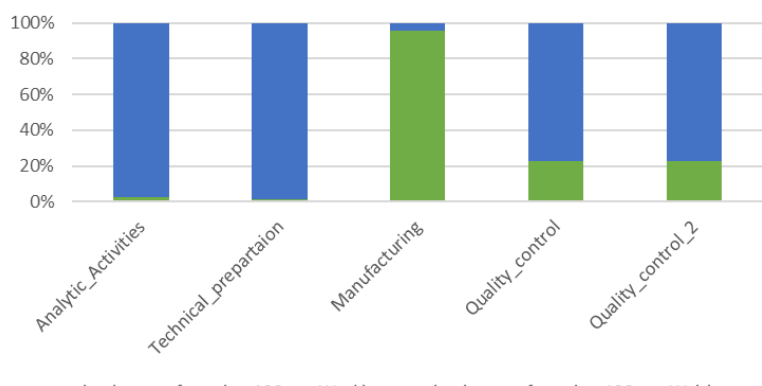

Fig. 8. Comparison of the production of for unit and small-lot production in batches of 10 and 100 pieces, in the classic and hybrid manufacturing process
Hybrid manufacturing - 1 pcs

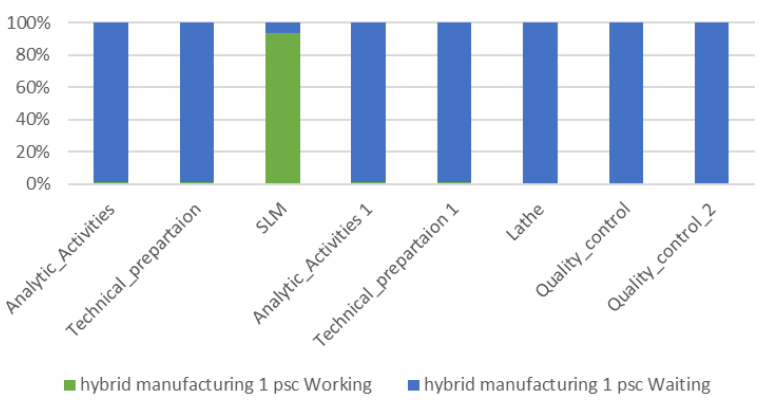

Hybrid manufacturing - 10 pcs

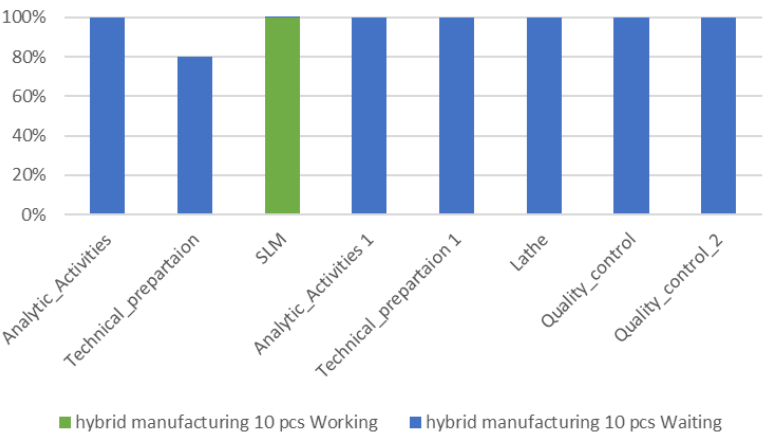

Hybrid manufacturing - 100 pcs

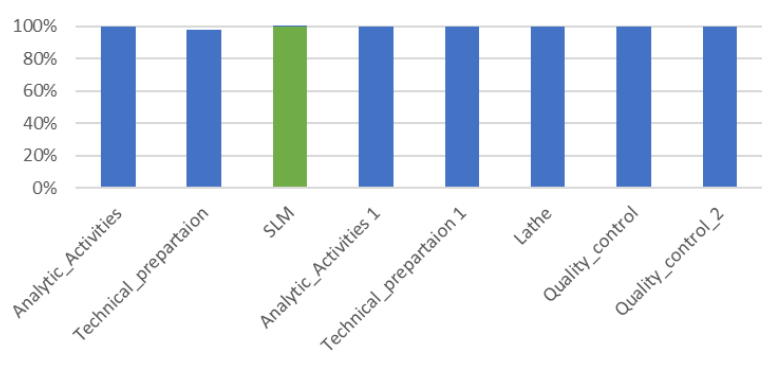

- hybrid manufacturing 100 pcs Working a hybrid manufacturing 100 pcs Waiting 
of the size of the production batch, analytic Activities and Technical preparation only occur once per process. Waiting time was characterized by a very high share, which is a waste in the process.

Electricity consumption analysis was carried out (Tables 4-5), in the hybrid manufacturing process for additive manufacturing SLM was confirmed the greatest demand for electricity. This due to the very long production time of the unit production ( 37 hours and 36 minutes), which has a direct impact on the rate of increase in electricity demand along with the increase in the production batch. The conducted result confirm the results obtained by Grzesiak et al in [31].

The costs of manufacturing a shield-type element for unit and small-lot production $10 \mathrm{pcs}$ and 100 pcs analysis was carried out for classic and hybrid manufacturing process (Table 6 ). The conducted research has shown that was recommended for unit production the use of hybrid production, which is used in particular in the production of spare parts for discontinued models of machines and vehicles. The production in the classical manufacturing process is $21 \%$ cheaper

Table 4. Electricity consumption for the classical manufacturing process

\begin{tabular}{|c|c|c|c|}
\hline \multicolumn{4}{|c|}{ Classic manufacturing process } \\
\hline \multirow[b]{2}{*}{ Object } & $1 \mathrm{pcs}$ & $10 \mathrm{pcs}$ & 100 pcs \\
\hline & $\begin{array}{c}\text { Total energy consumption } \\
\text { kWh }\end{array}$ & $\begin{array}{c}\text { Total energy consumption } \\
\text { kWh }\end{array}$ & $\begin{array}{c}\text { Total energy consumption } \\
\text { kWh }\end{array}$ \\
\hline Analytic activities & 0.19 & 0.19 & 0.19 \\
\hline Technical preparation & 0.09 & 0.09 & 0.09 \\
\hline Manufacturing & 4.36 & 43.63 & 435.28 \\
\hline Quality control & 0.13 & 0.25 & 2.50 \\
\hline Quality control 2 & 0.08 & 0.75 & 7.50 \\
\hline Sum & 4.84 & 44.91 & 445.55 \\
\hline
\end{tabular}

Table 5. Electricity consumption for the hybrid manufacturing process

\begin{tabular}{|l|c|c|c|}
\hline \multirow{2}{*}{ Object } & \multicolumn{2}{|c|}{ Hybrid manufacturing process } & 100 pcs \\
\cline { 2 - 4 } & $\begin{array}{c}\text { Total energy consumption } \\
\text { kWh }\end{array}$ & $\begin{array}{c}\text { Total energy consumption } \\
\text { kWh }\end{array}$ & $\begin{array}{c}\text { Total energy consumption } \\
\text { kWh }\end{array}$ \\
\hline Analytic Activities & 0.03 & 0.03 & 0.03 \\
\hline Technical preparation & 0.03 & 0.03 & 0.03 \\
\hline SLM & 54.90 & 548.96 & 5489.60 \\
\hline Lathe & 0.52 & 5.25 & 52.45 \\
\hline Quality control & 0.03 & 0.25 & 2.50 \\
\hline Quality control 2 & 0.08 & 0.75 & 7.50 \\
\hline Analytic Activities 1 & 0.03 & 0.03 & 0.03 \\
\hline Technical preparation 1 & 0.04 & 0.04 & 0.04 \\
\hline Sum & 55.65 & 555.33 & 5552.18 \\
\hline
\end{tabular}

Table 6. Cost comparison

\begin{tabular}{|l|c|c|c|c|c|c|}
\hline \multirow{2}{*}{ Description of the cost } & \multicolumn{2}{|c|}{ Classical manufacturing process } & \multicolumn{3}{c|}{ Hybrid manufacturing process } \\
\cline { 2 - 7 } & $1 \mathrm{pcs}$ & $10 \mathrm{pcs}$ & $100 \mathrm{pcs}$ & $1 \mathrm{pcs}$ & $10 \mathrm{pcs}$ & 100 pcs \\
\hline Operator's work & $67.89 \mathrm{PLN}$ & $328.09 \mathrm{PLN}$ & $2930.13 \mathrm{PLN}$ & $34.03 \mathrm{PLN}$ & $66.03 \mathrm{PLN}$ & $386.01 \mathrm{PLN}$ \\
\hline Technologist's work & $108.13 \mathrm{PLN}$ & $108.13 \mathrm{PLN}$ & $108.13 \mathrm{PLN}$ & $31.25 \mathrm{PLN}$ & $31.25 \mathrm{PLN}$ & $31.25 \mathrm{PLN}$ \\
\hline Quality controller's work & $13.44 \mathrm{PLN}$ & $134.40 \mathrm{PLN}$ & $1344.00 \mathrm{PLN}$ & $13.44 \mathrm{PLN}$ & $134.40 \mathrm{PLN}$ & $1344.00 \mathrm{PLN}$ \\
\hline Materials & $228.58 \mathrm{PLN}$ & $2285.80 \mathrm{PLN}$ & $22858.00 \mathrm{PLN}$ & $363.57 \mathrm{PLN}$ & $3635.70 \mathrm{PLN}$ & $36357.00 \mathrm{PLN}$ \\
\hline Cutting tools & $547.68 \mathrm{PLN}$ & $547.68 \mathrm{PLN}$ & $547.68 \mathrm{PLN}$ & $128.44 \mathrm{PLN}$ & $128.44 \mathrm{PLN}$ & $128.44 \mathrm{PLN}$ \\
\hline Electricity consumption & $3.00 \mathrm{PLN}$ & $27.86 \mathrm{PLN}$ & $276.38 \mathrm{PLN}$ & $34.52 \mathrm{PLN}$ & $344.47 \mathrm{PLN}$ & $3444.01 \mathrm{PLN}$ \\
\hline The total cost & $968.72 \mathrm{PLN}$ & $3431.95 \mathrm{PLN}$ & $28064.31 \mathrm{PLN}$ & $605.25 \mathrm{PLN}$ & $4340.29 \mathrm{PLN}$ & $41690.71 \mathrm{PLN}$ \\
\hline
\end{tabular}


in the small-lot production, as little as 10 pieces. The cost of classic manufacturing process in relation to hybrid production drops by $33 \%$ for the production of $100 \mathrm{pcs}$.

\section{RECAPITULATION}

The development of the Industry 4.0 concept and the epidemic situation in Europe and in the world forces enterprises to quickly reorganize production processes and flexible functioning of enterprises to the conditions of a changing competitive and universal environment. The article presents the concept of using a digital model to analyze the manufacturing process of a disc-type part and compare the effectiveness of traditional machining and a hybrid machining method combining additive manufacturing with machining. Simulation studies with the use of a digital model allowed for the assessment of these two production processes in terms of the following criteria order:

- fulfillment time,

- energy consumption,

- costs for unit and small-lot production in batches 10 and 100 pes.

In the hybrid process is:

- the fulfillment time is $580 \%$ longer,

- the energy consumption is 10.5 times greater,

- the costs of the hybrid production are $37.5 \%$ lower, than the production of the product using the classical method.

The obtained results allow to conclude that, taking into account the profitability criterion for unit production, the hybrid method is recommended. The conducted research confirmed the results obtained in the article by Grzesiak et al. [31] where unit production was analyzed. At the same time, the simulation studies carried out showed that for the production of 10 items of products, hybrid production is unprofitable, both in terms of time, production costs and energy consumption. The simulations show that in the case of small-lot production with as little as 10 items, the production in the traditional process is $21 \%$ cheaper, and for the production of 100 items, the cost of traditional production in relation to the hybrid production drops by $33 \%$.

It should be noted that in the simulation tests it was assumed that only one piece of the product is produced at a time at the SLM incremental manufacturing station. The study does not take into account the possibility of producing several products simultaneously. Undoubtedly, taking into account the possibility of making a greater number of products at the same time may shorten the time needed to manufacture the product. This problem will be considered in future studies. However, it should be noted, that the use of hybrid production is cost effective for unit production, which is particularly applicable in the production of spare parts for discontinued models of machines and vehicles for which spare parts are no longer produced.

\section{Acknowledgements}

This work was financed from the funds of the Ministry of Education and Science by Agreement No. DNK/SP/513880/2021 of 22 December 2021, the project " $14^{\text {th }}$ School of Machining and the $43^{\text {rd }}$ Scientific School of Abrasive Machining", under the programme "Perfect Science".

\section{REFERENCES}

1. Sarkis J. Supply chain sustainability: learning from the COVID-19 pandemic. IJOPM. 2020; 41(1): 63-73.

2. Sarkis J., Cohen M.J., Dewick P., Schröder P. A brave new world: Lessons from the COVID-19 pandemic for transitioning to sustainable supply and production. Resources, Conservation and Recycling. 2020; 159: 104894.

3. Kimura F., Thangavelu S.M., Narjoko D., Findlay C. Pandemic (COVID -19) Policy, Regional Cooperation and the Emerging Global Production Network. Asian Economic Journal. 2020; 34(1): 3-27.

4. Karmaker C.L., Ahmed T., Ahmed S., Ali S.M., Moktadir Md.A, Kabir G. Improving supply chain sustainability in the context of COVID-19 pandemic in an emerging economy: Exploring drivers using an integrated model. Sustainable Production and Consumption. 2021; 26: 411-427.

5. Chowdhury P., Paul S., Kaisar S., Abdul Moktadir Md. COVID-19 pandemic related supply chain studies: A systematic review. Transportation Research. Part E, Logistics and Transportation Review. 2021; 148: 102271-102271.

6. Chromjaková F., Bobák R., Hrušecká D. Production process stability - core assumption of INDUSTRY 4.0 concept. In: Proc of IOP Conference Series: Materials Science and Engineering. 2017: 215

7. Geissdoerfer M., Vladimirova D., Evans S. Sustainable Business Model Innovation: A Review. Journal of Cleaner Production. 2018; 198: 401-416. 
8. Breier M., Kallmuenzer A., Clauss T., Gast J., Kraus S., Tiberius V. The role of business model innovation in the hospitality industry during the COVID-19 crisis. International Journal of Hospitality Management. 2021; 92: 102723.

9. Haaker T., Ly P.T., Nguyen-Thanh N., Nguyen H.T. Business model innovation through the application of the Internet-of-Things: A comparative analysis. Journal of Business Research. 2021; 126: 126-136.

10. Martinez-Hernandez E., Leung Pah Hang M.Y., Leach M., Yang A. A framework for modeling local production systems with techno-ecological interactions: modeling local techno-ecological interactions. Journal of Industrial Ecology. 2017; 21(4): 815-828.

11. Hulkó G., Belavý C., Ondrejkovič K., Bartalský L., Bartko M. Control of technological and production processes as distributed parameter systems based on advanced numerical modeling. Control Engineering Practice. 2017; 66: 23-38.

12. Zakoldaev D.A., Shukalov A.V., Zharinov I.O., Zharinov O.O. The e-objects family in simulation of mechatronic facilities. IOP Conf Ser: Mater Sci Eng. 2020; 862: 042003.

13. Akpan I.J., Shanker M. The confirmed realities and myths about the benefits and costs of $3 \mathrm{D}$ visualization and virtual reality in discrete event modeling and simulation: A Descriptive Meta-Analysis of Evidence from Research and Practice Computers \& Industrial Engineering. 112: 197-211.

14. Goh M., Goh Y. M. Lean production theory-based simulation of modular construction processes. Automation in Construction. 2019; 101: 227-244.

15. Lugaresi G., Aglio G., Folgheraiter F., Matta A. Real-time validation of digital models for manufacturing systems: A novel signal-processing-based approach. In: IEEE 15th International Conference on Automation Science and Engineering (CASE). Vancouver, BC, Canada. 2019: 450-455.

16. Lugaresi G., Matta A. Real-time simulation in manufacturing systems: Challenges and research directions. In: 2018 Winter Simulation Conference (WSC). Gothenburg, Sweden 2018, 3319-3330.

17. Malega P., Gazda V., Rudy V. Optimization of production system in plant simulation. SIMULATION. August 2021.

18. Gola A., Pastuszak Z., Relich M., Sobaszek Ł., Szwarc E. Scalability analysis of selected structures of a reconfigurable manufacturing system taking into account a reduction in machine tools reliability. Eksploatacja i Niezawodność - Maintenance and Reliability. 2021; 23(2): 242-252.

19. Kikolski M. Study of production scenarios with the use of simulation models, Procedia Engineering. 2017; 182: 321-328.

20. Kłos S., Patalas-Maliszewska J. An analysis of the efficiency of a parallel-serial manufacturing system using simulation. In: Burduk A., Chlebus E., Nowakowski T., Tubis A. (eds) Intelligent Systems in Production Engineering and Maintenance. Advances in Intelligent Systems and Computing. 2018; 835: 32-43.

21. Grabowik C., Ćwikła G., Kalinowski K., Kuc M. A comparison analysis of the computer simulation results of a real production system. In 14th International Conference on Soft Computing Models in Industrial and Environmental Applications (SOCO 2019), Seville, Spain 2019, 344-354.

22. Zhang L., Zhou L., Ren L., Laili Y. Modeling and simulation in intelligent manufacturing. Computers in Industry. 2019; 112: 103123.

23. Strnad D., Fedorko G., Molnár V., Fialek P. Simulations as an assessment tool for the feasibility of logistics innovations motivated by the emergence of supply chain risk. Advances in Science and Technology Research Journal. 2021; 15(3): 66-75.

24. Roszkowski A., Piórkowski P., Skoczyński W., Borkowski W., Jankowski T. Study on the impact of cutting tool wear on machine tool energy consumption. Advances in Science and Technology Research Journal. 2020; 14(3): 158-164.

25. Liu D., Wang W., Wang L. Energy-efficient cutting parameters determination for NC machining with specified machining accuracy. Procedia CIRP. 2017; 61: 523-528.

26. Al Hazza M.H.F., Adesta, E.Y.T., Riza, M., Suprianto, M.Y. Power consumption optimization in CNC turning process using multi objective genetic algorithm. AMR. 2012; 576: 95-98.

27. Datta R., Majumder A. Optimization of turning process parameters using Multi-objective Evolutionary algorithm. In: Proc of IEEE Congress on Evolutionary Computation, Barcelona, Spain 2010, 1-6.

28. Newman ST., Nassehi A., Imani-Asrai R., Dhokia $\mathrm{V}$. Energy efficient process planning for CNC machining. CIRP Journal of Manufacturing Science and Technology. 2012; 5(2): 127-136.

29. Zhang H., Deng Z., Fu Y., Lv L., Yan C. A process parameters optimization method of multi-pass dry milling for high efficiency, low energy and low carbon emissions. Journal of Cleaner Production. 2017; 148: 174-184.

30. Shin S-J., Woo J., Rachuri S. Energy efficiency of milling machining: Component modeling and online optimization of cutting parameters. Journal of Cleaner Production. 2017; 161: 12-29.

31. Grzesiak D., Terelak-Tymczyna A., Bachtiak-Radka E., Filipowicz K. Technical and economic implications of the combination of machining and additive manufacturing in the production of metal parts on the example of a disc type element. In: Królczyk G., Niesłony P., Królczyk J. (eds) Industrial Measurements in Machining. IMM 2019. Lecture Notes in Mechanical Engineering. Springer, Cham. 2020; 128-137. 